\title{
Does Inside Trading Affect Managers' Decision-Making? A Theoretical Investigation
}

\author{
Ning Cao ${ }^{1}$, Shanmin $\mathrm{Li}^{1}{ }^{*}$, Yong $\mathrm{Li}^{2}$ \\ ${ }^{1}$ School of Business, Sun Yat-Sen University, Guangzhou, China \\ ${ }^{2}$ Hanqing Advanced Institute of Economics and Finance, Renmin University of China, Beijing, China \\ Email: "mnslsm@mail.sysu.edu.cn
}

Received 23 September 2015; accepted 14 November 2015; published 17 November 2015

Copyright (C 2015 by authors and Scientific Research Publishing Inc.

This work is licensed under the Creative Commons Attribution International License (CC BY). http://creativecommons.org/licenses/by/4.0/

(c) (1) Open Access

\section{Abstract}

This paper analyzes how inside trading affects managers' decision-making and also examines the effect of the social relations on managers. Through model analysis, the paper shows that inside trading does affect managers' behavior. Inside trading lowers the managers' minimum requirements for risky projects and thus has a risk-reduction effect on managers. In some cases, the existence of inside trading makes managers select projects with negative returns, which results in agency problems. When managers try to consolidate their social networks by divulging inside information, agency problems are exacerbated. This paper also analyzes the degree of risk aversion. As the degree of a manager's risk aversion increases, the risk-reduction effect of inside trading is reduced.

\section{Keywords}

Insider Trading, Risk Aversion, Agency Problem

\section{Introduction}

Rather than completely banning the practice, the United States and other developed countries seek to limit insider trading. Here, "insider trading" and "inside trading" have some differences. Insider trading refers to when insiders trade company stocks based on either public information or inside information. Inside trading only refers to trading based on inside information. Is inside trading harmful? Should it be forbidden? These questions have spurred academic debate. In China, since the establishment of the securities market, inside trading has been

${ }^{*}$ Corresponding author. 
closely watched by regulators and market participants. Many empirical studies point out the seriousness of inside trading in the Chinese stock market. Previously investigated and punished inside trading cases indicate that most cases involve the executives of the listed companies. Studies of these cases also show that insiders either trade stocks through other peoples' accounts rather than their own or divulge the inside information to other investors. Unlike America and Europe, China has its own pattern of inside trading. As such, research on the inside trading within the Chinese stock market has high academic value and practical significance.

Chinese stock market was born in the special period of economic reform. In the economic transition period, most people's understanding of the securities is superficial and one-sided. In addition, the regulatory system is not perfect and the market is immature, thus Chinese stock market is filled with all kinds of news. Inside trading is popular, the stock market has become a purely speculative gambling establishment.

According to a survey of Fortune Magazine, the main incomes of American executives are from bonuses and stock warrants and the basic salaries only occupy a very small proportion. But for the Chinese executives of listed companies, the salaries are the main source of income. With the single and unreasonable compensation structures, executives have strong incentives to find ways to increase their incomes. Making profits based on inside trading is an easy way to compensate their relatively low salaries. Besides the reason of inefficiency of the incentive mechanism, slack regulation also affects the behavior of executives. The supervision for financial markets form government is inadequate, so the insiders can easily escape punishments. In addition, there are many state-owned companies in Chinese stock market. For state-owned enterprises, "the absence of owners" is a long-standing problem and the "insider control" is serious, which increases the severity of inside trading in Chinese stock market.

This paper analyzes how inside trading affects managers' attitude towards projects. From the perspective of managers' utility maximization, we examine the effect of inside trading on managers' decision-making behavior. In our analysis, a manager needs to decide what type of projects should be chosen for the company. There are two types of projects, the risk-free projects and the risky project. Through modeling, we obtain the critical conditions for risky projects under different situations. The main conclusions are as follows. First, inside trading makes managers lower their minimum requirements for risky projects. Inside trading has a risk-reduction effect. Second, as the degree of the managers' risk aversion increases, the risk-reduction effect of inside trading is reduced. Third, if taking into account the second type of inside trading wherein a manager divulges inside information to others, the risk-reduction effect of inside trading may be further strengthened, and the manager may choose a project with a negative return. The result shows that inside trading may cause agency problems, and that managers' decisions may deviate from the goal of company value maximization.

The paper is organized as follows. Section 2 presents a review of past research and points out the logic behind this research. Section 3 describes the modeling process and the propositions deduced. Section 4 summarizes the research results and makes prospect for future research.

\section{Literature Review}

The academic study of inside trading can be traced back to Manne [1]. Manne first argued that inside trading can be regarded as a rewarding of managers that can encourage innovation, thereby increasing the value of the company. Since then, many researchers have built on Manne's theory. Carlton and Fischel [2] pointed out that inside trading provided beneficial returns to managers who were willing to take risks and created value for their companies. In this sense, inside trading can be regarded as a compensation mechanism that makes managers less conservative. In other words, inside trading can promote the most able and least risk-averse manager. Dye [3] points out that inside trading may be advantageous to each of the company's stakeholders. If managers are allowed to make compensation plans autonomously, managers and shareholders can obtain higher utility. If managers regard insider trading as a compensation mechanism, they can also create value for the company. Easterbrook [4] described the relationship between inside trading and agency problems. He also pointed out that insider trading can promote enthusiasm among managers and that including insider trading may be the optimal compensation plan for the company's management. Bebchuk and Fershtman [5] built a model and proved that under certain conditions, inside trading can increase the manager's level of effort, thereby increasing the company value. Bebchuk and Fershtman [6] pointed out that the existence of inside trading led a manager to choose riskier projects that would not otherwise be chosen. In some cases, inside trading can create greater value for the company. Noe [7] proposed a model and suggested that inside trading may increase the value of a company. 
Giving managers the opportunity of inside trading may operate as an alternative mechanism for compensation. Although inside trading may not make managers more hardworking, it is a more cost-efficient mode of compensation. Denis [8] pointed out that insider trading laws were one channel through which cross-country differences in pay practices might be explained. In countries with strong insider trading restrictions, managers have high income, and stock ownership incentive plans are general. Thus, in other contexts, insider trading can be regarded as a substitute for compensation.

Some researchers believe that inside trading does not have an incentive effect on managers. From the perspective of contracts, for example, Baiman and Verrecchia [9] modeled two types of agency problems. The first agency problem is that inside trading weakened the correlation between executive compensation paid by the shareholders and executive consumption, and as a result, shareholders have less control over the executives. The second type of agency problems is that managers can affect the stock price through inside trading, which can in turn affect compensation levels (compensation is always related to the stock price in contracts). Taking into account the ability of executives to manipulate stock prices, shareholders will lower the proportion of stock prices when signing contracts. There are many other arguments against inside trading. The main reasons are summarized as follows: 1) The stock price does not measure the value of manager activities accurately; 2) It is difficult to control the level of compensation; 3) It is difficult to tell whether inside trading occurs at the time the managers create value for the company or at other times.

Research on inside trading that is specific to the Chinese stock market commenced only recently. Early researchers on the Chinese context include Zhang and Zhu [10]. They collect the data on M\&A events in the Chinese stock market from January 1993 to June 2002. Using an event study, they tested the following assumptions: 1) Inside trading must exist in China; 2) Inside trading in China is more serious than in mature markets; 3) There exists a positive correlation between the degree of inside trading around a corporate event and the management's efforts in accomplishing the event; 4) Most inside trading occurs in response to good news.

Recently, many other Chinese scholars also have been studying inside trading. These researches primarily showed that the Chinese stock market had significant inside trading behavior and that divulging inside information was the main source of inside trading. Most previous researches are empirical, and fewer researches addressed the mechanism of inside trading. As inside trading data is not available, the existing empirical studies mostly comprised quantitative measures through the event study method. It is difficult to characterize the behavior of a specific transaction.

Additionally, most studies on other counties focused on insider trading, not on inside trading. As stated previously, insider trading refers to when insiders trade the company stocks based on either public information or inside information. Inside trading only refers to the trading based on inside information. Both domestic and foreign researchers have not fully considered cases involving the divulgence of inside information. Yet divulging inside information is very popular and largely determines the severity of inside trading, especially in the Chinese stock market.

In this study, from the mathematical viewpoint, we want to give a theoretical investigation to study the mechanism for inside trading. The social capital theory is used for analysis. Research on inside trading currently tends to utilize the theoretical framework of neoclassical economics. The theoretical framework of neoclassical economics presumes that people are rational and can allocate social resources in the most efficient way. However, existing research has frequently questioned the assumptions of neoclassical economics. Some scholars believe that the rationality hypothesis has a low applicability to social settings. The rationality hypothesis only considers personal motives and does not take the social environment or social system into account. In reality, people make decisions that are shaped by their social environment. Social relations are a very important factor in studies of inside trading. To use the concept of social relations, we need to first introduce social capital

In recent years, studies of economics have increasingly used the concept of social capital, which was first proposed by French sociologist Bourdieu [11]. Bourdieu posits that social capital is the sum of all kinds of social associations between individuals or groups. To obtain social capital, one must build and keep such social associations. Lin [12] proposed that social capital refers to the social resources that people can receive or use when they act and that social capital is thus embedded in social relations. People's behavior in their social environment is affected by their social relations. Social capital theory suggests that social relations can generate economic profit and that cost-benefits of relations can be calculated. A person's utility is not independent, but is rather affected by social relations and attendant aspects of those relations like emotion, trust, and other factors. Additionally, different social positions have different resources and differential access to useful information. 
Thus, one's social position affects one's social capital, which in turn affects behavior.

China is a society with an obvious "diversity-orderly structure" and "social circle."Ethics, emotion, and interest constitute the three dimensions of the pattern of the difference sequence of Chinese society. Chinese society pays special attention to kinship, which is formed through the family. It focuses especially on blood relations. As Chinese society takes seriously such human relationships, social relations should not be ignored in analyzing behavior. For insiders in a company, their social relations will affect their trading patterns. In this study, we examine how social relations affect inside trading behavior. Because the future return is uncertain, we also need to consider the degree of a manager's risk aversion in the modeling.

\section{The Model Analysis}

We refer to the modeling approach of Bebchuk and Fershtman [5]. From the perspective of managers' utility maximization, we examine the effect of inside trading on managers' decision-making behavior. In our analysis, a manager needs to decide what type of projects should be chosen for the company. In the process of model analysis, the paper will distinguish between different types of inside trading and consider the effect of social relations on managers. Previous academic research has addressed these aspects to a limited degree.

According to Chinese law, the definition of inside trading is that insiders, or people who receive inside information by illegitimate means, break the law by divulging inside information, giving trading suggestions to others, or using inside information to trade securities themselves. There are many types of insiders, including managers and other related stakeholders. In this study, we only focus on the managers of the listed firms. We discuss two types of inside trading behavior. The first type is when managers trade securities according to inside information. The second type is when managers divulge inside information to other investors. Through the first type of inside trading behavior, managers receive direct economic benefits from the exchange of stocks. The second type does not provide direct economic benefits, but can provide managers with benefits through other channels that can be regarded as invisible income. As mentioned, the insider can earn positive earnings in the future if he successfully manages his social network. Inside information can be viewed as an asset. Exchanging the asset within asocial network can strengthen relationships and thus result in the accumulation of additional economic benefits. Future economic benefits are regarded as currently invisible income in this paper.

The background of the model is as follows. Before time 0, the manager chooses a project (to simplify the analysis, we do not pay attention to the length of the period before time 0 ). At time 0 , a manager predicts the future condition. If inside trading is allowed, the manager can buy or sell securities according to his predictions. He can also divulge the information to others. The projects available for the firm are divided into two types, namely risk-free projects and risky projects. The risk-free project has certain future returns, and the risky project's future returns are uncertain. The risky project holds the possibility of higher income in good conditions and lower income in poor conditions.

Assume that in the initial state, the manager's holding ratio is $\alpha$. The manager's salary from time 0 to time 1 is $S$. If the manager chooses the risk-free project, he will continue to keep his proportion of the shares regardless of whether inside trading is allowed. If the manager chooses the risky project and the inside trading is allowed, the manager will buy $\beta$ ratio of shares if good conditions are predicted, or the manager will sell $\beta$ ratio of shares if poor conditions are predicted. In this study, we assume that $0<\alpha<1,0<\beta<1$, and $\beta<\alpha, \alpha+\beta<1$. For model simplification, we also assume $\frac{\beta}{\alpha}<\frac{1}{2}$.

The manager decides between two types of projects. The first is a risk-free project denoted by $P_{0}$, and the second is a risky project denoted by $P_{r}$. $P_{0}$ 's future return is certain. It will create value for the company. The value created is as below:

$$
Y=Y_{0}
$$

$P_{r}$ is risky, and the future return is uncertain. The value created for the company is as below:

$$
Y=Y_{0}+r+\omega
$$

$\omega$ is a random variable. It is positive with probability 0.5 and negative with probability 0.5 .

$$
\omega= \begin{cases}m & p=1 / 2 \\ -m & p=1 / 2\end{cases}
$$


$m$ is a positive constant. The greater the value of $m$, the greater the risk of the project. Here, suppose $m>r$, suggesting that in good conditions the return of a risky project is higher than the risk-free project and that in poor conditions, the return of the risky project is lower than the that of the risk-free project. In this study we also suppose $Y_{0} \gg m>r$. This suggests that the choice of risky project will not make the company value negative, and so the possibility of bankruptcy does not need to be considered.

The selected project ends at time 1 , and the results are clearly indicated. The firm value at time 0 is denoted as $V_{0}$, and the value at time 1 is denoted as $V_{1}$. The value added from time 0 to time 1 is created by the selected project, so $V_{1}-V_{0}=Y$.

The problem of which project to choose translates into the problem of maximizing the expected utility of the manager. As the future return is uncertain, the degree of the manager's risk-aversion needs to be considered when calculating expected utility. In this article, the degree of the manager's risk-aversion will be classified in detail.

The manager's expected utility function follows a common practice of economics. Suppose the manager's income at time 1 is $G$, then the manager's expected utility is as follows.

$$
E U(G)=E(G)-\delta \sigma(G)
$$

$\sigma(G)$ is the standard deviation of $G . \delta$ is a constant, and $0<\delta<1$, which represents the degree of the manager's risk-aversion. When the manager is risk neutral, $\delta=0$. The greater the degree of risk aversion, the greater the value of $\delta$.

1) The manager's decision-making without inside trading

The manager's utility is denoted as $U_{0}$ if he chooses the risk-free project and is denoted as $U_{r}$ if he chooses the risky project. First, we can easily calculate the expected utility when the manager chooses the risk-free project.

$$
E\left(U_{0}\right)=S+\alpha\left(V_{0}+Y_{0}\right)
$$

The calculation of expected utility is a little more complicated if the manager chooses the risky project $P_{r}$. We calculate the expectation and standard deviation of the manager's income.

$$
\begin{gathered}
E\left(G_{r}\right)=S+\frac{1}{2} \alpha\left(V_{0}+Y_{0}+r+m\right)+\frac{1}{2} \alpha\left(V_{0}+Y_{0}+r-m\right) \\
\delta\left(G_{r}\right)=\alpha m .
\end{gathered}
$$

According to Formula (4), we get

$$
E\left(U_{r}\right)=S+\alpha\left(V_{0}+Y_{0}+r\right)-\delta \alpha m
$$

then the question becomes: under what conditions will the manager choose the risky project $P_{r}$ ? From $E\left(U_{r}\right)>E\left(U_{0}\right)$ we can get $\alpha r-\delta \alpha m>0$, that is

$$
r>\delta m \text {. }
$$

So if the risky project satisfies $r>\delta m$, the manager will choose it.

Proposition 1: In the case that inside trading is not allowed, given the manager's risk aversion coefficient $\delta$, if the expected return and standard deviation of the risky project $P_{r}$ satisfy condition a: $r>\delta m$, the manager will choose the risky project $P_{r}$. Especially in the event that the manager is risk-neutral, if the risky project $P_{r}$ meets the condition $\boldsymbol{r}>\mathbf{0}$, the manager will choose $P_{r}$.

In the case that inside trading is not allowed, the manager will not choose a project with a negative expected return, no matter how large or small the manager's risk-aversion. Under this condition, the manager's decision does not deviate from the objective of maximizing corporate value. Next, we analyze how the manager makes decision with inside trading.

2) The manager's decision with the first type of inside trading

According to the assumption of the model, the manager will continue to maintain the $\alpha$ proportion of holdings if he chooses the risk-free project $P_{0}$ regardless of whether inside trading is allowed. Under the condition that the first type of inside trading is allowed, the manager's expected utility after choosing risk-free project $P_{0}$ is as below: 


$$
E\left(U_{0}\right)=S+\alpha\left(V_{0}+Y_{0}\right)
$$

When the manager chooses the risky project $P_{r}$, he has two choices. The first choice is to conduct inside trading. The second choice is to avoid inside trading. For each of the choices, if there is an expected utility larger than that of the risk-free project, the manager will choose the risky project. Here, $E_{1}\left(U_{r}\right)$ represents the expected utility with inside trading, and $E_{2}\left(U_{r}\right)$ represents the expected utility without inside trading. Correspondingly, $E_{1}\left(G_{r}\right)$ represents the expected return under the inside trading case, and $E_{2}\left(G_{r}\right)$ represents the expected return without inside trading.

$$
\begin{aligned}
E_{1}\left(G_{r}\right) & =S+\frac{1}{2}(\alpha+\beta)\left(V_{0}+Y_{0}+r+m\right)+\frac{1}{2}(\alpha-\beta)\left(V_{0}+Y_{0}+r-m\right) \\
& =S+\alpha\left(V_{0}+Y_{0}+r\right)+\beta m
\end{aligned}
$$

The standard deviation of the manager's income is as below:

$$
\sigma_{1}\left(G_{r}\right)=\alpha m+\beta\left(V_{0}+Y_{0}+r\right) .
$$

Substitute it into Formula (4) then we can get the expected utility

$$
\begin{aligned}
E_{1}\left(U_{r}\right)= & E_{1}\left(G_{r}\right)-\delta \sigma_{1}\left(G_{r}\right) \\
= & S+\alpha\left(V_{0}+Y_{0}+r\right)+\beta m-\delta \alpha m-\delta \beta\left(V_{0}+Y_{0}+r\right) \\
& E_{2}\left(U_{r}\right)=S+\alpha\left(V_{0}+Y_{0}+r\right)-\delta \alpha m .
\end{aligned}
$$

Then the question becomes whether the manager will choose the risky project $P_{r}$ if and only if $E_{1}\left(U_{r}\right)>E\left(U_{0}\right)$ or $E_{2}\left(U_{r}\right)>E\left(U_{0}\right)$. From $E_{1}\left(U_{r}\right)>E\left(U_{0}\right)$ we can get

$$
(\alpha-\delta \beta) r+(\beta-\delta \alpha) m-\delta \beta\left(V_{0}+Y_{0}\right)>0
$$

This can be simplified to

$$
r>\frac{\delta \beta}{\alpha-\delta \beta}\left(V_{0}+Y_{0}\right)+\frac{\delta \alpha-\beta}{\alpha-\delta \beta} m
$$

From $E_{2}\left(U_{r}\right)>E\left(U_{0}\right)$ we can get

$$
r>\delta m
$$

If the manager is risk-neutral, namely $\delta=0$, (16) translates into

$$
r>-\frac{\beta}{\alpha} m \text {. }
$$

Proposition 2: Under the condition that inside trading (the first type) is allowed, given the manager's risk aversion coefficient $\delta$, if the expected return and standard deviation of the risky project $P_{r}$ satisfy condition a: $r>\delta m$ or condition $\mathbf{b}: r>\frac{\delta \beta}{\alpha-\delta \beta}\left(V_{0}+Y_{0}\right)+\frac{\delta \alpha-\beta}{\alpha-\delta \beta} m$ then the manager will choose risky projects $P_{r}$. Particularly in the event that the manager is risk-neutral, if the risky project $P_{r}$ meets the condition $r>-\frac{\beta}{\alpha} m$, the manager will choose $P_{r}$.

Under the condition that inside trading (the first type) is allowed, the selection criteria for a risk-neutral manager is $r>-\frac{\beta}{\alpha} m$. There thus exists a possibility that the manager chooses a project with a negative expected return, which runs counter to the principle of company value maximization. Such a project would bring a negative expected income to the company. However, the manager can utilize bad news to obtain a trading profit, which results in inconsistency between the manager's decision-making and the goal of company value maximization. The analysis also indicates that the lower the degree of the manager's risk aversion, the greater the likelihood that a project with a negative return will be chosen. Namely, when inside trading is allowed, the risky project will be chosen if it satisfies condition a. When inside trading is forbidden, the risky project will be cho- 
sen if it satisfies either of the two conditions. Thus, inside trading expands the range of options. This effect can be regarded as a risk-reduction effect of inside trading. We proceed to discuss how the risk-reduction effect can be influenced by the degree of the manager's risk aversion.

3) The manager's decision with the two types of inside trading

The above analysis only considers the first type of inside trading, namely, when a manager utilizes inside information to trade stocks. The second type of inside trading is when a manager divulges inside information to other investors. Next, we analyze how a manager makes decisions about projects when the two types of inside trading are allowed. The manager's expected utility after choosing a risk-free project $P_{0}$ is as below:

$$
E\left(U_{0}\right)=S+\alpha\left(V_{0}+Y_{0}\right)
$$

If the manager chooses to engage in inside trading, Formula (13) becomes

$$
E_{1}\left(U_{r}\right)=S+W+\alpha\left(V_{0}+Y_{0}+r\right)+\beta m-\delta \alpha m-\delta \beta\left(V_{0}+Y_{0}+r\right) .
$$

Based on $E_{1}\left(U_{r}\right)>E\left(U_{0}\right)$, we can get

$$
r>\frac{\delta \beta}{\alpha-\delta \beta}\left(V_{0}+Y_{0}\right)-\frac{W}{\alpha-\delta \beta}+\frac{\delta \alpha-\beta}{\alpha-\delta \beta} m .
$$

When only the first type of inside trading is allowed, condition b is $r>\frac{\delta \beta}{\alpha-\delta \beta}\left(V_{0}+Y_{0}\right)+\frac{\delta \alpha-\beta}{\alpha-\delta \beta} m$. When the second type of inside trading is allowed, condition b becomes $r>\frac{\delta \beta}{\alpha-\delta \beta}\left(V_{0}+Y_{0}\right)-\frac{W}{\alpha-\delta \beta}+\frac{\delta \alpha-\beta}{\alpha-\delta \beta} m$, and the critical curve $r=\frac{\delta \beta}{\alpha-\delta \beta}\left(V_{0}+Y_{0}\right)-\frac{W}{\alpha-\delta \beta}+\frac{\delta \alpha-\beta}{\alpha-\delta \beta} m$ moves down compared with the former case. Namely, the manager has a broad range of choice for risky projects.

Proposition 3: Under the condition that two types of inside trading are allowed, given the manager's risk aversion coefficient $\delta$, if the expected return and standard deviation of the risky project $P_{r}$ satisfy condition a: $r>\delta m$ or condition $\mathbf{b}: r>\frac{\delta \beta}{\alpha-\delta \beta}\left(V_{0}+Y_{0}\right)-\frac{W}{\alpha-\delta \beta}+\frac{\delta \alpha-\beta}{\alpha-\delta \beta} m$, then the manager will choose risky projects $P_{r}$. Especially when the manager is risk-neutral, if the risky project $P_{r}$ meets the condition $r>-\frac{\beta}{\alpha} m-\frac{W}{\alpha}$, then the manager will choose $P_{r}$. The disclosure of inside information can strengthen the risk-reduction effect of inside trading, and thus, the manager will have a broad range of choice for risky projects.

From the above analysis, we find that the existence of inside trading changes the manager's attitude towards projects. The main conclusions are as follows: a) Inside trading lowers the manager's minimum requirement for the risky project by having a risk-reduction effect. When the manager is risk-neutral or has a low degree of risk-aversion, there exists a possibility that the manager chooses a risky project with negative expected return. b) As the degree of the manager's risk-aversion increases, inside trading's risk-reduction effect is reduced. c) If taking into account the second type of inside trading — divulging inside information to others—-the risk-reduction effect of inside trading will be strengthened.

From the perspective of corporate governance, the existence of inside trading make it possible to choose a risky project with a negative expected return, thus causing an agency problem. The manager can benefit from the company's bad news, and in so doing, his decision-making can run counter to the maximization of company value. The manager's decision in such an instance is shaped by the maximization of individual interests. In some cases, this will cause losses to the company.

4) The effect of the degree of the manager's risk-aversion

From the above analysis, we know that when inside trading is not allowed, the critical condition of choosing risky project is $r>\delta m$. When the first type of inside trading is allowed, the critical condition of choosing risky project is $r>\frac{\delta \beta}{\alpha-\delta \beta}\left(V_{0}+Y_{0}\right)+\frac{\delta \alpha-\beta}{\alpha-\delta \beta} m$ or $r>\delta m$. Thus, the critical functions all contain the coefficient 
$\delta$. We proceed to examine how the degree of risk-aversion affects a manager's decision-making and then focus on whether risk aversion increases or decreases the effect of inside trading.

First, examine how the risk aversion coefficient $\delta$ affects the condition a of the former propositions (Figure 1).

The horizontal axis represents the standard deviation of the risky project. The vertical axis represents the expected return of the risky project. Draw the line $l_{1}$. The function of $l_{1}$ is $r=\delta m$. This is a straight line passing through the origin and its slope is $\delta$. The region above $l_{1}$ and within the first quadrant is called $R_{1}$. If the risky project falls into the region $R_{1}$, the manager will choose it. When the manager is risk-neutral, $l_{1}$ will coincide with the horizontal axis and the region $R_{1}$ will coincide with the first quadrant. As the degree of risk-aversion increases, the area of the region $R_{1}$ decreases, indicating that the manager raises the minimum requirement for the risky project.

Next, analyze how the degree of risk aversion affects condition b. The horizontal axis still represents the standard deviation, and the vertical axis still represents the expected return. Draw the line

$l_{2}: r=\frac{\delta \beta}{\alpha-\delta \beta}\left(V_{0}+Y_{0}\right)+\frac{\delta \alpha-\beta}{\alpha-\delta \beta} m$. The nature of the line will be influenced by the risk aversion coefficient $\delta$, and so there are different situations.

a) When $\delta=0$, the critical curve $l_{2}$ is $r=-\frac{\beta}{\alpha} m$. This is a straight line passing through the origin, and its slope is negative( Figure 2(a)).

b) When $0<\delta<\frac{\beta}{\alpha}, \frac{\delta \alpha-\beta}{\alpha-\delta \beta}<0$, the critical curve $l_{2}$ is $r=\frac{\delta \beta}{\alpha-\delta \beta}\left(V_{0}+Y_{0}\right)+\frac{\delta \alpha-\beta}{\alpha-\delta \beta} m$. This is a straight line passing through $\left(0, \frac{\delta \beta}{\alpha-\delta \beta}\left(V_{0}+Y_{0}\right)\right)$, and its slope is negative (Figure 2(b)).

c) When $\delta=\frac{\beta}{\alpha}$, the critical curve $l_{2}$ is $r=\frac{\delta \beta}{\alpha-\delta \beta}\left(V_{0}+Y_{0}\right)$. This is a straight line passing through $\left(0, \frac{\delta \beta}{\alpha-\delta \beta}\left(V_{0}+Y_{0}\right)\right)$, and it is parallel to the horizontal axis (Figure 2(c)).

d) When $\frac{\beta}{\alpha}<\delta<1, \frac{\delta \alpha-\beta}{\alpha-\delta \beta}>0$, the critical curve is $r=\frac{\delta \beta}{\alpha-\delta \beta}\left(V_{0}+Y_{0}\right)+\frac{\delta \alpha-\beta}{\alpha-\delta \beta} m$. This is a straight line passing through $\left(0, \frac{\delta \beta}{\alpha-\delta \beta}\left(V_{0}+Y_{0}\right)\right)$, and its slope is positive(Figure 2(d)).

From Figure 3, we can see that the critical line of condition b rotates upward as the risk aversion coefficient $\delta$ increases. Both the intercept and the slope are increasing. Both can be seen as a function of $\delta$. The domain is $\delta \in[0,1)$. The intercept function is $\mu(\delta)=\frac{\delta \beta}{\alpha-\delta \beta}\left(V_{0}+Y_{0}\right)$. This function is an increasing function of $\delta$ $\delta$, and the range is $\mu(\delta) \in\left[0, \frac{\beta}{\alpha-\beta}\left(V_{0}+Y_{0}\right)\right)$. The slope function is also an increasing function of $\delta$, and
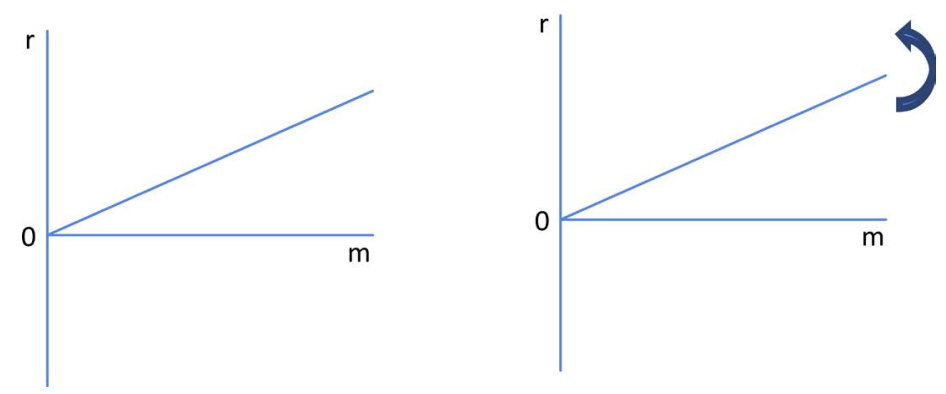

Figure 1. The graphical analysis of condition a. 


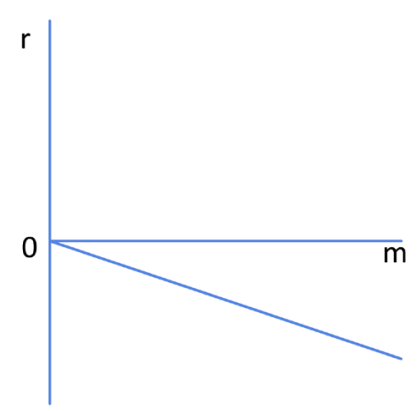

(a)

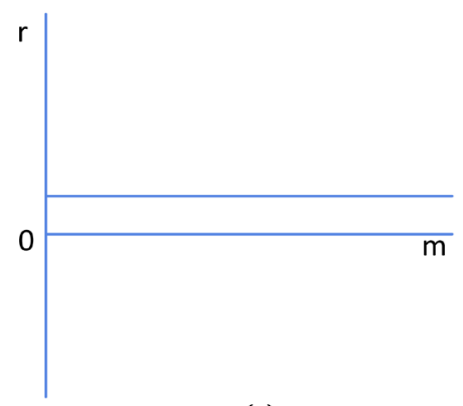

(c)

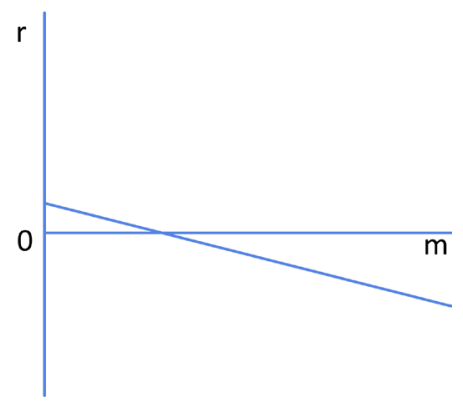

(b)

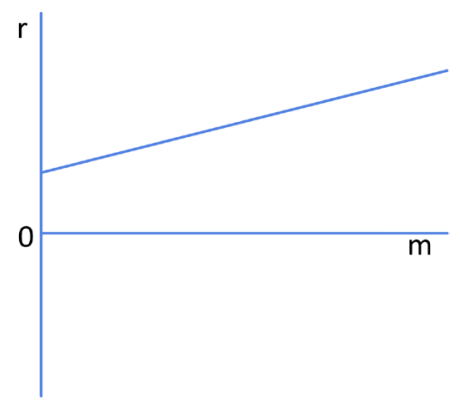

(d)

Figure 2. The critical curve of condition b. (a) $(\delta=0)$; (b) $\left(0<\delta<\frac{\beta}{\alpha}\right)$; (c) $\left(\delta=\frac{\beta}{\alpha}\right)$; (d) $\left(\frac{\beta}{\alpha}<\delta<1\right)$.

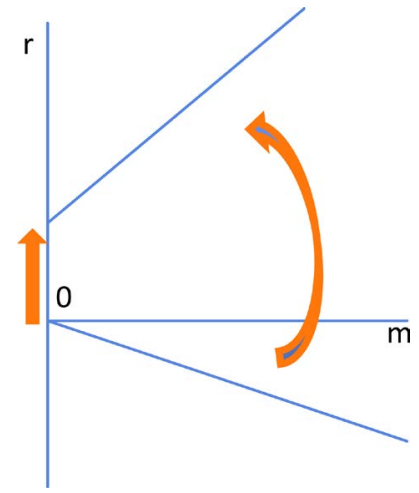

Figure 3. The changing trend of the critical line $l_{2}$.

the range is $\varphi(\delta) \in\left[-\frac{\beta}{\alpha}, 1\right)$. This implies that as the degree of the manager's risk-aversion increases, the range of choice for risky projects decreases.

Next, place condition a and condition b together, and examine the effect of the risk aversion coefficient. From Figures 4(a)-(d), we can see that no matter what interval the risk aversion coefficient is in, the range of choice in cases of inside trading is larger than the range of choice in cases without inside trading. This means that the existence of inside trading leads the manager to lower his minimum requirement for the risky project. Conversely, as the risk aversion coefficient $\delta$ increases, the range of choice for a risky project decreases, which means that the risk-reduction effect of inside trading is weakened.

Proposition 4: Given the manager's risk aversion coefficient, the existence of inside trading leads the manager to lower his minimum requirement for a risky project. Thus, inside trading has a risk-reduction effect.

Proposition 5: In cases where inside trading is allowed, for a risk-neutral manager, if the risky project 


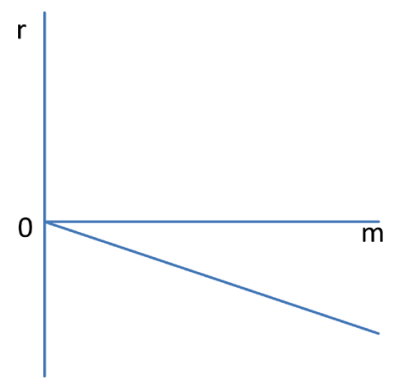

(a)

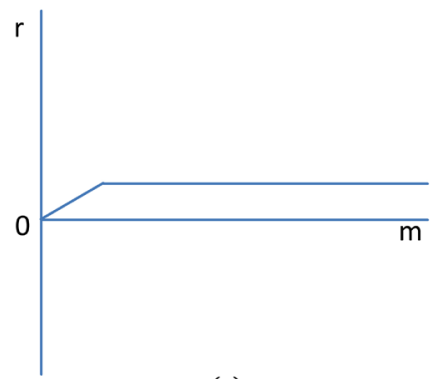

(c)

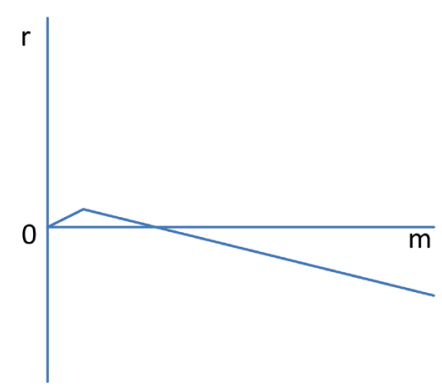

(b)

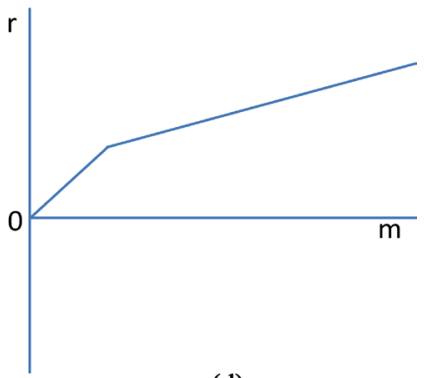

(d)

Figure 4. The critical curve of condition a \& b. (a) $\left(\delta=\frac{\beta}{\alpha}\right)$; (b) $\left(0<\delta<\frac{\beta}{\alpha}\right)$; (c) $\left(\delta=\frac{\beta}{\alpha}\right)$; (d) $\left(\frac{\beta}{\alpha}<\delta<1\right)$.

satisfies $r>-\frac{\beta}{\alpha} m$, the manager will choose it. As the manager's risk aversion coefficient increases, his minimum requirement for a risky project will be raised, meaning that the risk-reduction effect of inside trading decreases. Particularly in cases where a manager has a relatively low degree of risk aversion, there exists the possibility that the manager chooses a risky project with a negative expected return. When the manager has a relatively high degree of risk aversion, the manager will not select a risky project with a negative expected return.

The five propositions explain inside trading's effect from different aspects and they are related to each other. The first proposition describes the equilibrium in the case of inside trading is not permitted. The second and third propositions describe the equilibrium under conditions that inside trading is allowed. The fourth and fifth propositions describe the effect of the managers' risk aversion degree. These five propositions complement each other and jointly make a judgment on inside trading.

5) Discussion of the Model

In this study, we build a model to analyze how inside trading affects the behavior of managers. Through examining managers' attitudes towards risky projects, we conclude that inside trading will cause agency costs. When a manager is motivated to consolidate relationships in his social network by divulging inside information, his decision may deviate from the principle of company value maximization. We also conclude that the existence of inside trading can relax the risk-averse attitude of a manager when making project selections. In other words, inside trading has a risk-reduction effect.

Although the definition of inside trading includes the behavior of divulging inside information, theoretical and empirical studies rarely consider this type of inside trading behavior. In model analysis, social relations are particularly difficult to describe and measure. Thus, researchers only consider managers' own transactions. However, Chinese society pays special attention to social relations, which heavily affect economic decision-making. It is therefore imperative not to neglect social relations, and this article tries to take into this aspect of decision-making into account. Although the measurement method is relatively simple, it is a new approach. The model shows that if a manager has the motivation to consolidate his social network through divulging inside information to others, the inside trading will be more significant and may result in losses to the company.

Previously investigated and punished inside trading cases show that divulging inside information is very popular. Insiders trade stocks through other peoples' accounts or divulge the inside information to other investors. 
Additionally, in China, social relations have a strong influence on managers. In order to consolidate his social network, a manager has a strong incentive to divulge inside information to others. There is also the possibility that the invisible income obtained through divulging inside information is larger than the income obtained through the manager's own transactions.

This paper also importantly concludes that inside trading can relax a manager's attitude towards a risky project. This is a double-edged sword. Under good conditions, the existence of inside trading can greatly enhance the value of a company. However, under poor conditions, it will damage the interests of the company. This suggests that inside trading simultaneously increases a manager's risk tolerance and company risk. Many scholars believe that inside trading has a significant incentive effect on managers. However, this paper points out that the incentive effect is conditional and not universally applicable.

There are some shortcomings to this paper and directions for future research. The model assumes that a manager first makes a choice and that he can later learn whether the conditions are good or poor. This means that a manager makes decisions before he can predict future conditions. Therefore, the manager will take risks when making decision in cases of uncertainty. There are also other considerations one might take into account in building the model. For instance, if a manager makes a decision when there is no uncertainty, then how does inside trading affect his behavior? In this line of inquiry, we can examine the manager's level of effort or other decision-making. We can also consider the role of social relations. Perhaps such research will yield interesting results.

The analysis of social relations also requires further development. In recent years researchers focusing on Chinese economics have become acquainted with the word "guanxi," which has a meaning similar to "connection" or "relation." China's economic system has frequently been described as "socialism with Chinese characteristics." There are many differences between China and other developed countries. To take these differences into account, in future studies, we will try to describe guanxi, social relations and social networks in detail and comprehensively model the process of inside trading.

Moreover, in this paper we do not introduce the factor of regulation. The goal of this research is to evaluate inside trading, and we accordingly focus on the effect of inside trading on the managers. Future studies will consider the regulatory elements.

Additionally, this paper only considers one type of insiders. However, in practice, there are many other types of insiders, including government officials, financial institution staff, and so on. Deeper analysis of inside trading by these insiders is needed.

Finally, this article is theoretical, and there is no empirical analysis. Many of the conclusions in this paper might be demonstrated through further empirical research.

\section{Conclusions}

This paper analyzes how inside trading affects managers' attitude towards projects. Through modeling, we obtain the critical conditions for risky projects under different situations. The main conclusions are as follows: 1) Inside trading makes managers lower their minimum requirements for risky projects. Inside trading has a risk-reduction effect; 2) As the degree of the managers' risk aversion increases, the risk-reduction effect of inside trading is reduced; 3) If taking into account the second type of inside trading which a manager divulges inside information to others, the risk-reduction effect of inside trading may be further strengthened, and the manager may choose a project with a negative return. The result shows that inside trading may cause agency problems, and that managers' decisions may deviate from the goal of company value maximization.

In summary, although many scholars contend that inside trading is an effective incentive method, this paper rejects that conclusion. In some cases, inside trading will bring losses to the company. It should thus be strictly regulated. However, because of the existence of social networks, managers may benefit not only from their own transactions but also from divulging inside information to others. Divulging inside information may worsen an agency problem and incurlosses for the company. In China, the disclosure of inside information is very serious. Regulating inside trading is a difficult problem that requires more effective supervision by the relevant regulatory authorities.

\section{Funding}

This research is supported by Chinese National Science Fund "Study on Insider Trading in M\&A and Restruc- 
turing of Chinese listed companies” under No.71372149.

\section{References}

[1] Manne, H.G. (1966) Insider Trading and the Stock Market. The Free Press, New York.

[2] Carlton, D.W. and Fischel, D.R. (1983) The Regulation of Insider Trading. Stanford Law Review, 35, 857-895. http://dx.doi.org/10.2307/1228706

[3] Dye, R.A. (1984) Insider Trading and Incentives. Journal of Business, 57, 295-313. http://dx.doi.org/10.1086/296265

[4] Easterbrook, F.H. (1981) Insider Trading, Secret Agents, Evidentiary Privileges, and the Production of Information. The Supreme Court Review, 1981, 309-365.

[5] Bebchuk, L.A. and Fershtman, C. (1993) The Effects of Insider Trading on Insiders' Effort in Good and Bad Times. European Journal of Political Economy, 9, 469-481. http://dx.doi.org/10.1016/0176-2680(93)90034-R

[6] Bebchuk, L.A. and Fershtman, C. (1994) Insider Trading and the Managerial Choice among Risky Projects. Journal of Financial and Quantitative Analysis, 29, 1-14. http://dx.doi.org/10.2307/2331187

[7] Noe, T.H. (1997) Insider Trading and the Problem of Corporate Agency. Journal of Law, Economics, and Organization, 13, 287-318. http://dx.doi.org/10.1093/oxfordjournals.jleo.a023385

[8] Denis, D.J. and Xu, J. (2013) Insider Trading Restrictions and Top Executive Compensation. Journal of Accounting and Economics, 56, 91-112. http://dx.doi.org/10.1016/j.jacceco.2013.04.003

[9] Baiman, S. and Verrecchia, R.E. (1995) Earnings and Price-based Compensation Contracts in the Presence of Discretionary Trading and Incomplete Contracting. Journal of Accounting and Economics, 20, 93-121. http://dx.doi.org/10.1016/0165-4101(94)00377-H

[10] Zhang, X. and Zhu, H.M. (2003) The Economic Analysis of Insider Trading. China Economic Quarterly, 3, 72-96.

[11] Bourdieu, P. (1977) Outline of a Theory of Practice. Cambridge University Press, Cambridge. http://dx.doi.org/10.1017/CBO9780511812507

[12] Lin, N., Cook, K.S. and Burt, R.S. (2001) Social Capital: Theory and Research. Transaction Publishers, Piscataway. http://dx.doi.org/10.1017/CBO9780511815447 